\title{
ABSORÇÃO DE ÁGUA E POTENCIAL FISIOLÓGICO EM SEMENTES DE SOJA DE DIFERENTES TAMANHOS
}

\author{
Osmar Paulo Beckert1 ${ }^{1,2,5 *}$; Marcelo Hissnauer Miguel ${ }^{3,5}$; Júlio Marcos Filho ${ }^{4,5}$ \\ ${ }^{1}$ Embrapa-Serviço de Negócios para Transferência de Tecnologia, C.P. 97 - CEP: 84001-970 - Ponta Grossa, PR. \\ ${ }^{2}$ Depto. de Fitotecnia e Fitossanidade - UEPG, C.P. 992/3 - CEP: 84010-330 - Ponta Grossa, PR. \\ ${ }^{3}$ Pós-Graduando do Depto. de Produção Vegetal - USP/ESALQ. \\ ${ }^{4}$ Depto. de Produção Vegetal - USP/ESALQ, C.P. 9 - CEP: 13418-900 - Piracicaba, SP. \\ ${ }^{5}$ Bolsistas CNPq. \\ *Autor correspondente <opbecker@carpa.ciagri.usp.br>
}

RESUMO: A absorção de água por sementes de soja, em função do tamanho, ocorre em diferentes intensidades podendo ter relação com seu potencial fisiológico. A marcha de absorção de água em sementes de soja e sua relação com o potencial fisiológico foram avaliados no presente trabalho. Sementes do cultivar BRS-155 foram classificadas, com base na espessura, em peneiras de crivos oblongos $(6,75 ; 6,35 ; 5,95 ; 5,55 ; 5,15 ; 4,75$ e $4,35 \times 19 \mathrm{~mm}$ ). As retidas nas peneiras 6,35; 5,55 e 4,75 x $19 \mathrm{~mm}$ foram submetidas à hidratação controlada (pré-condicionamento) com posterior secagem até atingirem o grau de umidade inicial. A evolução da hidratação foi avaliada por meio da pesagem das sementes de três em três horas, em oito períodos e 5 repetições, e, o potencial fisiológico, pelos testes de germinação, envelhecimento acelerado e condutividade elétrica, antes e após a hidratação. As sementes submetidas à hidratação apresentaram diferenças de qualidade, em relação às não hidratadas, exclusivamente no teste de condutividade elétrica. Entre os diferentes tamanhos, as sementes retidas na peneira 4,75 mostraram qualidade inferior às demais no tratamento sem hidratação, em todos os testes e, com exceção do envelhecimento acelerado sem hidratação, as retidas na peneira $5,55 \mathrm{~mm}$ apresentaram potencial fisiológico superior às dos demais tamanhos. A absorção de água é mais intensa em sementes menores e, de modo geral, as sementes de tamanho menor ou maior em $0,79 \mathrm{~mm}$ em relação às de tamanho médio, são de qualidade inferior.

Palavras-chave: Glycine max, embebição, germinação, vigor

\section{WATER UPTAKE BY DIFFERENT SOYBEAN SEED SIZES AND PHYSIOLOGICAL QUALITY}

\begin{abstract}
Water uptake of soybean seeds, depending on seed size, occur at different intensities and can be related to the physiological potential. With the purpose of determining the pattern of water uptake of soybean seeds and its relationship to their physiological potential, one soybean seed lot, CV. BRS-155, was separated into different sizes (6.75; 6.35; 5.95; 5.55; 5.15; 4.75 e 4.35 x 19 mm). Seed sizes $6.35 ; 5.55$ and 4.75 mm were submited to a slow hydration (pré-conditioning) and dried to the original water content. Water uptake was evaluatad at $20^{\circ} \mathrm{C}$ in samples of 130 seeds distributed on a suspended wire-mesh screen inside a plastic box, with the addition of $20 \mathrm{ml}$ of water. Initial water content was evaluated through drying, and the imbibition rate through weighting the seeds after $3,6,9,12,15,18,21$ e 24 hours, in 5 replications. Physiological quality was evaluated through standard germination, accelerated aging and electrical conductivity tests, before and after water uptake. Among the different sizes, smaller seeds had lower physiological quality in the treatment without conditioning and, except for the accelerated aging without conditioning, medium seed size had the best performance. Water uptake was more intense in smaller seeds. In general, the smallest or largest seeds were of lower quality than those of medium size.
\end{abstract}

Keywords: Glycine max, water uptake, germination, vigor, seed size

\section{INTRODUÇÃO}

Para que uma semente germine, é necessário que o meio forneça água suficiente, permitindo a ativação das reações químicas relacionadas ao metabolismo e, com isto, a retomada do processo do desenvolvimento do embrião. A embebição é um processo físico, relacionado com as propriedades dos colóides, e ocorre tanto em sementes vivas quanto mortas (Mayer \& Mayber, 1978; Copeland \& McDonald, 1995).
Sob condições ideais de suprimento de água, a absorção pelas sementes obedece a um padrão trifásico. $\mathrm{Na}$ fase I, denominada embebição, ocorre uma rápida entrada de água, em função da grande diferença de potencial entre as sementes e o substrato, independentemente do estado fisiológico das sementes. $\mathrm{Na}$ fase II, a velocidade de absorção de água se torna mais lenta, tendendo para o equilíbrio entre os potenciais; ocorrem diversas reações metabólicas preparatórias à emergência da raiz primária. $\mathrm{Na}$ fase III, com o metabolismo ativado e em função da produção de 
substâncias osmoticamente ativas, ocorre uma redução no potencial hídrico das sementes, resultando em rápida absorção de água do meio (Bewley \& Black, 1994).

Os principais componentes químicos das sementes, responsáveis pela embebição e aumento de tamanho, são as proteínas, e, em menor intensidade, a celulose e substâncias pécticas; o amido e os lipídios apresentam interferência reduzida no processo (Mayer \& Mayber, 1978; Copeland \& McDonald, 1995).

O tegumento das sementes exerce papel importante na embebição; quando esta é impedida, em virtude da impermeabilidade do tegumento, a germinação não ocorre (Bradford, 1995). McDonald et al. (1988) mostraram que, durante as primeiras oito horas de embebição, o tegumento das sementes de soja atua regulando a passagem da água; após este período, torna-se totalmente permeável, podendo inclusive servir como reservatório de água para uso do eixo embrionário. Rocha et al. (1984), avaliando a capacidade de absorção de água por sementes de soja, verificaram que as sementes de colheita retardada tiveram elevação na velocidade de embebição em relação às obtidas de colheitas em época adequada, sugerindo que sementes deterioradas embebem mais rapidamente.

Em trabalhos relacionados com embebição, considerando-se diferentes tamanhos de sementes, tem sido constatado que as sementes de menor tamanho atingem teores de água superiores aos observados para sementes de maior tamanho (Calero et al., 1981; Hsu et al., 1983; Souza, 1996); esse fato está relacionado à maior área de contato por unidade de massa, nas sementes menores.

A influência do tamanho das sementes tem sido estudada, visando identificar diferenças de qualidade; os resultados encontrados são divergentes. Edward \& Hartwig (1971), trabalhando com três linhagens isogênicas de soja, verificaram que as sementes de menor tamanho germinaram e emergiram mais rapidamente. Aguiar (1978), classificando sementes de soja em peneiras de crivos circulares, constatou que as sementes, cuja largura foi inferior em $0,79 \mathrm{~mm}$ ou superior em $0,4 \mathrm{~mm}$ às de tamanho médio, apresentaram qualidade semelhante ou inferior a estas, concordando com Wetzel (1978). Este autor constatou que as sementes menores, em $0,79 \mathrm{~mm}$, que as médias foram inferiores quanto à germinação, vigor, velocidade de crescimento e produção, comparadas às de tamanho médio. Em ambos os casos, como a quantidade de sementes que se enquadravam nos tamanhos menores era muito pequena, sua remoção não provocaria benefícios significativos à germinação e ao vigor do lote de sementes. Thomas \& Costa (1996) observaram que sementes de soja de menores tamanho e peso, originaram plântulas menos vigorosas. Entretanto, outros pesquisadores trabalhando com parâmetros idênticos, não encontraram diferenças na qualidade das sementes de diferentes tamanhos (Krzyzanowski et al., 1991; Silva Filho, 1994).

A hidratação controlada vem sendo utilizada em leguminosas como método de pré-condicionamento (envigoramento), tanto para sementes deterioradas (envelhecidas) como para sementes altamente sensíveis aos danos durante a embebição rápida, ou interação entre ambos, objetivando melhorar o desempenho destas (Powell, 1998). A hidratação lenta pode ainda ser seguida de secagem, se as sementes não tiverem atingido a fase III da germinação, facilitando o subsequente manuseio, armazenamento e semeadura com equipamentos convencionais (Copeland \& McDonald, 1995).

França Neto et al. (1998), avaliando a sensibilidade de sementes de diversos cultivares de soja aos danos durante a embebição no teste de germinação, verificaram que alguns cultivares responderam positivamente ao pré-condicionamento, enquanto outros não apresentaram respostas positivas.

Saha et al. (1990), aplicando diferentes métodos de hidratação controlada em sementes de soja, notaram que, imediatamente após a hidratação - secagem, não houve incrementos significativos na porcentagem de germinação e no vigor (comprimento de raiz e de plântula), comparados com a testemunha não hidratada. Porém, após o envelhecimento natural sob condições ambientais durante 5 meses, a germinação foi superior nas sementes pré-condicionadas.

O presente trabalho teve como objetivos avaliar a marcha de absorção de água e a influência da hidratação controlada, como método de pré-condicionamento, sobre a qualidade de sementes de soja, classificadas em diferentes tamanhos.

\section{MATERIAL E MÉTODOS}

A pesquisa foi conduzida no Laboratório de Sementes do Departamento de Produção Vegetal da Escola Superior de Agricultura Luiz de Queiroz, Universidade de São Paulo, em Piracicaba/SP.

Foram utilizadas sementes de soja, cultivar BRS-155, com teor de água de $10 \%$, classificadas pela espessura, através da sobreposição de peneiras de crivos oblongos $(6,75 ; 6,35 ; 5,95 ; 5,55 ; 5,15 ; 4,75$ e 4,35 x $19 \mathrm{~mm})$ cuja proporção em peso de ocorrência de cada tamanho no lote foi zero, 5,4, 23,1, 33,8, 28,1, 7,5 e 2,1\%, respectivamente. Foram utilizadas as sementes retidas nas peneiras 6,$35 ; 5,55$ e $4,75 \times 19 \mathrm{~mm}$, além da testemunha (sementes não classificadas). As sementes foram tratadas com Thiram SC, na dosagem de $140 \mathrm{~g}$ i.a/100 kg sementes. Em seguida, as amostras de cada tamanho foram divididas em duas partes; metade foi utilizada para a realização das avaliações, sem sofrer a hidratação controlada e, a outra, submetida à hidratação.

A hidratação controlada foi conduzida colocando-se 130 sementes sobre a tela suspensa no interior de caixa plástica, normalmente utilizada como mini-câmara para 0 teste de envelhecimento acelerado, contendo $20 \mathrm{ml}$ de água. As caixas foram colocadas em germinador regulado a 20 $\mathrm{C}$ e, a cada 3 horas, foi determinado o teor de água das sementes, através da pesagem das amostras, até completar o período de $24 \mathrm{~h}$. 
Imediatamente após a embebição, as sementes foram colocadas para secar em estufa com circulação de ar, a $35^{\circ} \mathrm{C}$ por 9 horas, até atingirem teor de água próximo do inicial. $O$ grau de umidade inicial foi avaliado pelo método da estufa a $105^{\circ} \mathrm{C}$, durante $24 \mathrm{~h}$, de acordo com as Regras para Análise de Sementes (Brasil, 1992).

O teste de germinação foi conduzido em 4 repetições de 50 sementes para cada tratamento, a $25^{\circ} \mathrm{C}$, conforme as Regras para Análise de Sementes (Brasil, 1992). As contagens foram realizadas aos 4 e 7 dias após a semeadura.

Para o teste de condutividade elétrica foram utilizadas 3 repetições de 50 sementes de cada tratamento, previamente pesadas em balança com precisão de $0,01 \mathrm{~g}$, imersas em $75 \mathrm{ml}$ de água destilada, por um período de $24 \mathrm{~h}$, a $25^{\circ} \mathrm{C}$, conforme Vieira (1994). Os resultados foram expressos em $\mu \mathrm{mho} \mathrm{cm}^{-1} \mathrm{~g}^{-1}$.

O envelhecimento acelerado foi executado empregando-se caixas plásticas (mini-câmaras) contendo $40 \mathrm{ml}$ de água. Sobre a tela, foram colocadas 240 sementes e, as caixas, mantidas a $41^{\circ} \mathrm{C}$, por $48 \mathrm{~h}$, conforme Marcos Filho (1994). Em seguida as sementes foram submetidas ao teste de germinação, com avaliação no quarto dia após a semeadura.

Os dados de germinação foram transformados em arc sen $(x / 100)^{0,5}$ e, juntamente com os dados de condutividade elétrica, submetidos a análise de variância, com as médias comparadas pelo teste de Duncan a $5 \%$ de probabilidade.

\section{RESULTADOS E DISCUSSÃO}

As sementes de tamanhos menores apresentaram embebição mais rápida que as de maior tamanho, já a partir de $3 \mathrm{~h}$, com as retidas na peneira $4,75 \mathrm{~mm}$ apresentando superioridade de 1,3 ponto percentual de água neste período (TABELA 1). Esta diferença foi se acentuando até o período final (24h), quando as sementes de tamanho 4,75 apresentaram 3,4 e 1,6 ponto percentual a mais de água em relação às de tamanho 6,35 e 5,55 respectivamente, o que pode estar relacionado tanto com o tamanho quanto com o potencial fisiológico apresentado pelas sementes menores que, em função de estarem mais deterioradas, estariam com as membranas mais permeáveis à entrada de água nas primeiras horas da embebição. Esses dados são comparáveis aos obtidos por Calero et al. (1981), que encontraram em diversos genótipos de soja, correlação negativa entre o tamanho da semente e a velocidade e intensidade de absorção de água; de acordo com esses autores, a observação pode estar relacionada com uma maior proporção em peso do tegumento em relação ao peso da semente, associada a um maior número de poros por unidade de área. Também Hsu et al. (1983) encontraram esta mesma relação, embora atribuindo o fato a uma maior área de contato das sementes de menor tamanho, por unidade de massa. Por outro lado, Souza (1996) verificou maior rapidez de embebição nas primeiras horas em sementes de Calopogonium mucunoides com menor tamanho, o que estaria relacionado com o estado de deterioração destas.

A germinação das sementes (TABELA 2) não apresentou diferenças significativas entre os tratamentos com e sem hidratação controlada, concordando com Vasques (1995); no entanto, contrariaram as observações de Puteh et al. (1995), ao verificarem que o précondicionamento incrementou a germinação em sementes de soja, bem como as de Armstrong \& McDonald (1992) que obtiveram germinação inferior nas sementes précondicionadas e submetidas a secagem, em relação às sem condicionamento. Contudo, entre os diferentes tamanhos, as sementes retidas na peneira 5,55 apresentaram porcentagem de germinação significativamente superior, tanto nos tratamentos sem, quanto nos com pré-condicionamento. Por outro lado, as sementes menores (P 4,75) apresentaram a menor porcentagem de germinação (TABELA 2), concordando com Aguiar (1978), Wetzel (1978), e Souza (1996). Este fato pode estar relacionado com a presença, nesta fração, de uma maior porcentagem de sementes mal formadas, devido à ocorrência de doenças, insetos ou de condições ambientais desfavoráveis durante a fase de produção. Entretanto, Krzyzanowski et al. (1991) e Silva Filho (1994) não encontraram diferenças entre os potenciais fisiológicos de sementes classificadas por tamanho.

Quando submetidas ao envelhecimento acelerado (TABELA 2), as sementes pré-condicionadas apresentaram melhor desempenho, com as de tamanho 5,55 qualitativamente superiores às de tamanho 4,75 e 6,35, e as de tamanho 4,75 apresentando uma tendência de qualidade inferior em relação às de tamanho 6,35 , porém

TABELA 1 - Teor de água de sementes de soja, tamanhos 4,75, 5,55, 6,35 x $19 \mathrm{~mm}$ e testemunha, submetidas a 8 períodos de embebição à $20^{\circ} \mathrm{C}$.

\begin{tabular}{|c|c|c|c|c|c|c|c|c|c|}
\hline \multirow[b]{2}{*}{ Tamanhos } & \multicolumn{9}{|c|}{ Períodos de embebição (h) } \\
\hline & 0 & 3 & 6 & 9 & 12 & 15 & 18 & 21 & 24 \\
\hline $\mathrm{mm}$ & ----- & - & $-\cdots$ & - & $---\%$ & ------ & $-\cdots$ & ---- & 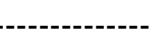 \\
\hline 4,75 & 10,3 & 12,8 & 14,4 & 15,9 & 17,2 & 17,8 & 18,9 & 19,9 & 20,9 \\
\hline 5,55 & 10,5 & 12,6 & 13,9 & 15,1 & 16,1 & 16,8 & 17,7 & 18,5 & 19,3 \\
\hline 6,35 & 10,0 & 11,5 & 12,8 & 13,9 & 14,8 & 15,4 & 16,2 & 16,9 & 17,5 \\
\hline TEST. & 10,1 & 11,8 & 13,1 & 14,3 & 15,3 & 16,3 & 17,2 & 18,0 & 18,9 \\
\hline
\end{tabular}


TABELA 2 - Potencial fisiológico de sementes de soja, tamanhos 4,75, 5,55, 6,35 x 19 mm e testemunha, sem embebição controlada (SEC) e com embebição controlada (CEC), avaliada pelos testes de germinação (G), envelhecimento acelerado (EA) e condutividade elétrica (CE).

\begin{tabular}{|c|c|c|c|c|c|c|}
\hline \multirow[t]{2}{*}{ Tamanhos } & \multicolumn{2}{|c|}{ G } & \multicolumn{2}{|c|}{ E A } & \multicolumn{2}{|c|}{$\mathrm{CE}$} \\
\hline & SEC & CEC & SEC & CEC & SEC & CEC \\
\hline $\mathrm{mm}$ & \multicolumn{4}{|c|}{ 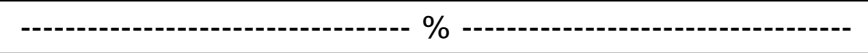 } & \multicolumn{2}{|c|}{$\left(\mu \mathrm{mho} \mathrm{cm}^{-1} \mathrm{~g}^{-1}\right)$} \\
\hline 4,75 & $71 \mathrm{cA}$ & $69 \mathrm{cA}$ & $60 \mathrm{bA}$ & $56 \mathrm{cA}$ & $183.76 \mathrm{aA}$ & $166.92 \mathrm{aB}$ \\
\hline 5,55 & 86 aA & $85 \mathrm{aA}$ & $61 \mathrm{bB}$ & $73 \mathrm{aA}$ & $137.29 \mathrm{bA}$ & $114.90 \mathrm{cB}$ \\
\hline 6,35 & $80 \mathrm{bA}$ & $75 \mathrm{bA}$ & $66 \mathrm{abA}$ & $60 \mathrm{bcA}$ & $145.22 \mathrm{bA}$ & $135.58 \mathrm{bA}$ \\
\hline TEST. & $77 \mathrm{bA}$ & $82 \mathrm{bA}$ & $71 \mathrm{aA}$ & $67 \mathrm{abA}$ & $146.58 \mathrm{bA}$ & $132.04 \mathrm{bB}$ \\
\hline CV (\%) & \multicolumn{2}{|c|}{6.3} & \multicolumn{2}{|c|}{6.4} & \multicolumn{2}{|c|}{4.1} \\
\hline
\end{tabular}

*Letras minúsculas: comparações dentro de cada coluna; letras maiúsculas: comparações dentro de cada linha (teste de Duncan, a 5\%).

significativamente inferior à testemunha, na qual há predominância de sementes de tamanho médio. Entre os tratamentos com e sem embebição, com exceção das sementes de tamanho 5,55, não houve diferença significativa, concordando com resultados obtidos por Vasques (1995), que submeteu sementes de soja a embebição controlada por 24 horas seguida de secagem e observou que não houve diferença na qualidade fisiológica (envelhecimento acelerado) entre estas e a testemunha não hidratada.

As sementes submetidas ao pré-condicionamento, apresentaram uma menor lixiviação de eletrólitos comparada às sementes sem condicionamento, exceto as de tamanho 6,35, confirmando dados obtidos por Armstrong \& McDonald (1992) e Vasquez (1995), o que pode ser atribuído aos efeitos do umedecimento na ativação de mecanismos de reparo das membranas nas sementes condicionadas, fazendo com que estas se encontrassem mais organizadas em relação às sem précondicionamento, dificultando a lixiviação de solutos para o meio. Entre os diferentes tamanhos, as sementes do tratamento com hidratação controlada e tamanho intermediário (P 5,55) foram as que apresentaram a menor lixiviação de solutos e, a exemplo do que ocorreu no teste de envelhecimento acelerado, nas sementes précondicionadas foi possível classificar o potencial fisiológico em função dos diferentes tamanhos; as retidas na peneira 5,55 apresentaram qualidade superior (menor lixiviação) e as retidas na peneira 4,75 a pior qualidade (maior lixiviação). Já nas sementes sem pré-condicionamento, a liberação de eletrólitos foi significativamente superior nas sementes de tamanho 4,75 , sendo que as demais não apresentaram esta diferença, concordando com Aguiar (1978), Wetzel (1978) e Souza (1996), em cujos trabalhos as sementes pequenas foram as de qualidade inferior $\mathrm{e}$ discordando de Krzyzanowski et al. (1991) e Silva Filho (1994), que não observaram diferença de qualidade fisiológica entre as sementes dos diferentes tamanhos.

De acordo com as proporções de sementes apresentadas no lote, a eliminação das sementes de tamanho $4,75 \mathrm{~mm}$, no beneficiamento, representaria uma quebra de $7,5 \%$ e seria suficiente para enquadrar o lote quanto à germinação mínima, nos padrões oficiais para comercialização. Caso também fossem removidas as sementes de tamanho $6,35 \mathrm{~mm}$, isto representaria uma quebra adicional de $5,4 \%$ do total do lote que, considerando-se grandes volumes de produção de sementes, pode representar uma diminuição significativa de receita, embora com ganhos significativos de qualidade.

Pôde-se observar no presente trabalho a importância do aproveitamento das sementes cujo tamanho não diferiu acentuadamente das situadas nos limites de tamanho médio, procurando-se eliminar os extremos, principalmente o inferior, o que contribuiu para o incremento do potencial fisiológico do lote de sementes.

\section{CONCLUSÕES}

A intensidade e velocidade de absorção de água pelas sementes de soja, cv. BRS-155 é inversamente proporcional ao tamanho. As sementes menores ou maiores em $0,79 \mathrm{~mm}$ em relação às de tamanho médio no lote, apresentam potencial fisiológico inferior.

\section{REFERÊNCIAS BIBLIOGRÁFICAS}

AGUIAR, P.A.A. Efeito do tamanho da semente na germinação e vigor de soja (Glycine max (L.) Merrill). In: SEMINÁRIO NACIONAL DE PESQUISA DE SOJA, 1., Londrina, 1978. Anais. Londrina: EMBRAPA, CNPSo, 1979. v.2, p.232-235.

ARMSTRONG, H.; McDONALD, M.B. Effects of osmoconditioning on water uptake and electrical conductivity in soybeans seeds. Seed Science and Technology, v.20, p.391-400, 1992.

BEWLEY, J. D.; BLACK, M. Seeds: physiology of development and germination. New York: Plenum Press, 1994. 445p.

BRADFORD, K. J. Water relations in seed germination. In: KIGEL, Y.; GALILI, G. (Ed.) Seed development and germination. New York: Marcel Dekker, 1995. cap.3, p.351-356.

BRASIL. Ministério da Agricultura. Regras para análise de sementes. Brasília: SNDA, DNDV, CLV, 1992. 365p.

CALERO, E.; WEST, S.H.; HINSON, K. Water absortion of soybean associated causal factors. Crop Science, v.21, p.926-933, 1981. 
COPELAND, L.O.; McDONALD, M.B. Principles of seed science and technology. 3. ed. New York: Chapman \& Hall, 1995. 409p.

EDWARD JR. C.J.; HARTWIG, E.E. Effect of seed size upon rate of germination in soybeans. Agronomy Journal, v.63, p.429-430, 1971.

FRANÇA NETO, J.B.; KRZYZANOWSKI, F.C.; HENNING, A.A.; COSTA, N.P. Suscetibilidade das principais cultivares de soja utilizadas no Brasil ao dano de embebição no teste de germinação. Londrina: Embrapa Soja, 1998. 10p. (Comunicado Técnico, 60).

HSU, K.H.; KIM, C.J.; WILSON, L.A. Factors affecting water uptake of soybean during soaking. Cereal Chemistry, v.60, p.208-211, 1983.

KRZYZANOWSKI, F.C.; FRANÇA NETO, J.B.; COSTA, N.P. Efeito da classificação de sementes de soja por tamanho sobre sua qualidade e a precisão de semeadura. Revista Brasileira de Sementes, v.13, p.59-68, 1991.

MARCOS FILHO, J. Teste de envelhecimento acelerado. In: VIEIRA, R.D.; CARVALHO, N.M. (Coord.). Testes de vigor em sementes. Jaboticabal: FUNEP, 1994. p.133-149.

MAYER, A.M.; MAYBER, A.P. The germination of seeds. 2.ed. Oxford: Pergamon Press, 1978. 192p.

McDONALD, M.B.; VERTUCCI, C.W.; ROOS, E.E. Soybean seed imbibition: water absortion by seeds parts. Crop Science, v.28, p.993-997, 1988.

POWELL, A.A. Seed improvement by selection and invigoration. Scientia Agricola, v.55, p.126-133, 1998. Número especial.

PUTEH, A.B.; TEKRONY, D.M.; EGLI, D.B. Influence of temperature and water uptake on the expression of cotyledon necrosis in soybean [Glycine $\max ($ L.) Merrill]. Seed Science and Technology, v.23, p.739-748, 1995.
ROCHA, V.S.; SEDIYAMA, T.; DA SILVA, R.F.; SEDIYAMA, C.S.; THIEBAUT, J.T.L. Embebição de água e qualidade fisiológica de sementes de soja. Revista Brasileira de Sementes, v.6, p.51-66, 1984.

SAHA, R.; MANDAL, A.K. BASU, R.N. Physiology of seed invigoration treatments in soybean (Glycine max L.). Seed Science and Technology, v.18, p.269-276, 1990.

SILVA FILHO, P.M. Desempenho de plantas e sementes de soja classificadas por tamanho e densidade. Pelotas, 1994. 64p. Dissertação (Mestrado) - Universidade Federal de Pelotas.

SOUZA, F.H.D. Características físicas das sementes de Calopogonium mucunoides Desv. associadas à qualidade fisiológica e ao padrão de absorção de água: I. Tamanho. Revista Brasileira de Sementes, v.18, p.33-40, 1996

THOMAS, A.L.; COSTA, J.A. Influência do déficit hídrico sobre o tamanho das sementes e vigor das plantulas de soja. Pesquisa Agropecuária Gaúcha, v.2, p.57-61, 1996.

VASQUEZ, G.H. Condicionamento fisiológico de sementes de soja: efeitos sobre a germinação, vigor e potencial de armazenamento. Piracicaba, 1995. 138p. Dissertação (Mestrado) - Escola Superior de Agricultura Luiz de Queiroz, Universidade de São Paulo.

VIEIRA, R.D. Teste de condutividade elétrica. In: VIEIRA, R.D.; CARVALHO, N.M. (Coord.) Testes de vigor em sementes. Jaboticabal: FUNEP, 1994 . p.133-149.

WETZEL, C.T. Efeito do tamanho das sementes de soja. In: SEMINÁRIO NACIONAL DE PESQUISA DE SOJA, 1., Londrina, 1978. Anais. Londrina: EMBRAPA, CNPSo, 1979. v.2, p.333-341.

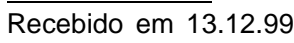

